\title{
LA IDENTIDAD CULTURAL DEL NEGRO EN LAS NOVELAS DE QUINCE DUNCAN. ASPECTOS TEMATICOS Y TECNICOS
}

\author{
POR \\ EDWIN SALAS ZAMORA \\ Universidad Nacional, Costa Rica
}

\section{INTRODUCCIÓN}

El negro como personaje ya había sido novelado en la literatura costarricense con anterioridad a la década de los setenta. Fallas, en Mamita Yunai, había esbozado, desde los años cuarenta, lo que podría denominarse una visión sociológica de la situación de los negros en la Zona Atlántica, bajo los efectos de la actividad bananera. Si bien Fallas era un profundo conocedor de esa problemática étnica y social, su visión tenía necesariamente un énfasis en lo social y económico y no en el aspecto personal y psicológico, ello debido obviamente a los objetivos de su creación. Esta es la mayor diferencia con los personajes novelescos de Quince Duncan, quienes no sólo son víctimas de los vaivenes de la actividad económica, sino que son presentados más integralmente: con sus problemas económicos y sociales, pero también con sus conflictos psicológicos, étnicos y culturales. Es una constante en sus novelas el que las generaciones mayores vivan la nostalgia de sus tierras de origen y que no abandonen la esperanza del regreso, aun cuando esto sea ilusorio. Los jóvenes viven ese conflicto como una crisis personal que no los deja integrarse definitivamente a su situación presente ni los motiva un regreso a una tierra que ni siquiera conocen.

Otra constante fuerte en los relatos de este autor es la lucha desigual del negro con la naturaleza adversa. Las inundaciones constituyen un verdadero azote para los agricultores negros, quienes se ven constantemente lanzados a reconstruir lo que habían hecho, en un auténtico castigo de Sísifo. Y a pesar de que anhelan desplazarse hacia la meseta central, no pueden abandonar esa tierra donde viven. ¿Temor? ¿Apego al grupo étnico? La conciencia étnica se convierte, a veces, en un problema de sobre- 
vivencia: quizá juntos puedan sobrevivir mejor. Los que se aventuran a transgredir esos límites culturales, que también son geográficos, sufren las consecuencias que tan bien recrea Quince Duncan en sus relatos: la discriminación, la miseria, las burlas y las crisis de identidad. Por eso los personajes de sus novelas, al poco tiempo de haber dejado su tierra natal, vuelven a ella, ¿a buscar respuesta?, ¿a liquidar su pasado revalorizándolo a la luz de la experiencia? Es posible; pero también hay añoranza, deseo de revivir detalles de la niñez y la juventud, necesidad de respirar en un ambiente todavía considerado propio y sobre todo conocido.

Para algunos, las obras de Duncan no reflejan con autenticidad a la cultura negra. Esto puede ser un problema de percepciones distintas. De hecho, el autor ha tenido que adoptar un idioma que no es el de esa cultura que él recrea; además, probablemente sus relatos no se escriban directamente para negros. Pero no se puede negar una cosa tan evidente como la capacidad de observación y de recreación que él pone de manifiesto en sus escritos. Tampoco se puede negar su capacidad de elaboración artística, que lo coloca a la altura de sus contemporáneos.

La temática que aborda Quince Duncan es digna, en muchos aspectos, del realismo social de los años cuarenta, pero la elaboración literaria de sus novelas responde a otro momento. Es la superación del realismo y de la visión predominantemente social de una problemática y, a la vez, el desarrollo de la introspección. Definitivamente, Duncan escapa a la crítica, en muchos casos injustificada, que se hacía a los escritores de la novela social hispanoamericana, por el hecho de crear personajes que sólo eran espejo de una problemática social. Los personajes de este autor son de una gran hondura psicológica, son contemporáneos: por sus angustias, por sus crisis, por sus indefiniciones. Igualmente contemporánea es su concepción de la novela como una actividad de escritura que no se debe ocultar. En esto también difiere del realismo, ya que, al lado de los acontecimientos novelescos, desarrolla la crítica del mismo texto: con referencias irónicas al lenguaje, con discusiones sobre modos de decir, con referencia a otros textos. Todo ello pone de manifiesto esa conciencia de la escritura que distingue al novelista contemporáneo.

En 1971, Duncan publica Hombres curtidos, novela en que ya se anuncia con fuerza el conflicto entre el «aquí y el «allá», auténtico leit-motiv de su narrativa. El personaje, después de catorce años de ausencia, regresa a su pueblo natal. Se reviven momentos de la vida de otros personajes relacionados con el protagonista narrador: abuelos, padre, tíos, amigos. Cobra mucha importancia la identidad cultural, aun entre los jóvenes. Los viejos añoran Jamaica. Se da una pugna con respecto a la importancia de conservar los rasgos culturales afrocaribeños. Asimismo, se destaca la 
inclemencia de la región atlántica y el apego de los hombres a esa tierra. El protagonista recuerda las calamidades que pasó en la capital, cuando no podía conseguir trabajo por ser negro. Al final, cuando parece que el personaje ha venido a su pueblo a tomar venganza de una ofensa inferida a su padre, le confiesa a su esposa que él vino a escribir la biografía del abuelo, y aquí el protagonista narrador empieza a contar esa historia, que resulta ser la misma que se ha venido desarrollando en la novela, con lo cual el principio y el final de Hombres curtidos coinciden: «El acto de levantar la valija, alzar al niño y bajarme del tren es uno solo...» ${ }^{1}$.

En 1973 se publica la novela Los cuatro espejos, que será analizada con algún detalle más adelante.

La paz del pueblo es editada en 1978. En esta novela, en contrapunto con un conflicto amoroso, se hacen referencias a los orígenes africanos y caribeños de algunos personajes. El asunto amoroso se vuelve trágico cuando Cato, un amante desesperado por el desprecio de la bella Sitaira, termina por matarla, y todos le incriminan el hecho a Pedro Dull, un dirigente obrero a quien ella ha entregado su amor. Los amigos de Pedro le aconsejan huir, puesto que el jefe político también lo acusa de incitar a los trabajadores de Mr. Brown a la huelga; pero él decide entregarse a la autoridad, y con este acto mueve a algunos hombres a atestiguar en su favor. Este hecho es importante porque simboliza el inicio de una conciencia social entre los hombres del pueblo. También se hace alusión, en el relato, al traslado de las actividades bananeras del Atlántico al Pacífico y a la prohibición que tienen los negros de trasladarse a esa nueva zona. Está presente, asimismo, la situación climática del Atlántico: calor, inundaciones y barro.

En 1979 se publica Final de calle. Esta es una novela cuya temática no es ya la situación del negro limonense, profundizada en obras anteriores. Se trata de la reconstrucción de una serie de momentos de la guerra civil de 1948, vista a través de muchos personajes que tomaron parte en la misma. Al presentar las vivencias de esos personajes se logra una especie de equilibrio entre las distintas versiones de lo que sucedió y por qué sucedió. Hay personajes representantes de la oligarquía, del calderonismo, el comunismo y la socialdemocracia.

La visión de Carlos López, un ex-combatiente social-demócrata, es la que engloba todo el relato y deja, al final, una actitud escéptica sobre si valió la pena «cruzar los cerros» para luchar, pues ahora su hijo Daniel es apaleado por enrolarse en una manifestación anti-imperialista. Este es-

${ }^{1}$ Quince Duncan, Hombres curtidos (San José, Costa Rica: Cuadernos de Arte Popular, Imprenta Metropolitanna, 1971), p. 140. 
cepticismo del protagonista se da a través de un monólogo que constituye una autorrecriminación del personaje.

E1 uso del «tú» como desdoblamiento, así como la variabilidad del punto de vista constituyen dos rasgos novedosos en esta novela. También es interesante la imbricación de un relato en otro y de éste en un tercero, por la variedad de voces e instancias que incluye. El desplazamiento de la visión de un personaje a otro produce un desarrollo de la historia en contrapunto, lo cual también es reforzado por constantes retrospecciones. El conjunto es un relato variado, que logra responder a una realidad, pero que a la vez sorprende a esa misma realidad dándole una organización novedosa.

Quince Duncan también escribió relatos breves: Una canción en la madrugada, de 1970; Cuentos del hermano Araña, de 1975; La rebelión pocomía, de 1976, y cuentos sueltos en diversas revistas. Asimismo es autor de diversos ensayos y estudios.

\section{«LOS CUATRO ESPEJOS»}

Se hace un análisis más detallado de esta obra porque la consideramos la más representativa de la producción de Duncan, tanto en su aspecto temático cuanto en lo relativo a las técnicas narrativas. La consideración de algunas de éstas pondrá de manifiesto el manejo que de ellas tiene el autor y permitirá ubicarlo dentro de las tendencias actuales de la narrativa hispanoamericana.

El argumentos de la novela es el siguiente: Charles McForbes, un joven negro, descendiente de jamaicanos y oriundo de la provincia de $\mathrm{Li}$ món, se casa con Lorena Sam, una muchacha negra del pueblo. Con ella vive seis años, dedicado al cultivo del cacao y al ejercicio ocasional del pastorado evangélico. Unos vecinos, con quienes Charles tiene problemas, logran embrujar a Lorena y ésta contrae una extraña enfermedad, a causa de la cual muere después de estar un año en el hospital. A partir de aquí, Charles abandona la plantación, busca trabajo y se relaciona con varias mujeres. Un día decide abandonar el pueblo e irse a la ciudad capital para tratar de estudiar. Vende la pequeña plantación y le entrega el dinero a una de las mujeres, con la cual había tenido un hijo. En la ciudad realiza estudios universitarios, con la ayuda del señor Lucas Centeno, un médico que tuvo como paciente a Lorena. Pasado algún tiempo, Charles y Ester, una hija del señor Centeno, se enamoran y se casan, a pesar de la oposición familiar por ser él negro. Todo va bien para Charles hasta que un día escucha una conferencia sobre minorías raciales en Costa 
Rica, y a raíz de esto sufre una crisis de identidad: no puede ver su rostro en el espejo. Se va de la casa, vagabundea por la ciudad en busca de médicos, se embriaga y entra a un club nocturno, luego sale y pasa la noche caminando sin rumbo fijo. Por fin decide regresar a su pueblo natal, creyendo que encontrará sus raíces culturales y, por tanto, su identidad. Al llegar encuentra todo cambiado y comprende que no es posible vivir ahí. Regresa a la ciudad y va a su casa. Al encontrar a su esposa comprende que ése es su lugar en la vida: se mira al espejo y puede ver su rostro.

Además de este hilo central se desarrollan otras historias paralelas. La primera es la relativa a otro hombre negro, compañero juvenil de Charles y luego enemigo. Se llama Christian Bowman y de él sospecha Charles que fue quien embrujó a Lorena. En realidad, lo hizo la esposa de Bowman, llamada Nabe, quien preparó el hechizo para Lorena por celos con su esposo. Christian, al saber de la enfermedad de Lorena, se va en busca de un hechicero para que la cure, pues él la ama y además Lorena tuvo un hijo con él. De este personaje se conoce su origen, sus creencias y sus problemas familiares. Otra de las historias es la de los antepasados de Ester, gente de alcurnia y muy representativa a nivel nacional. Fueron cafetaleros de mucho renombre en la política y la cultura. Ya con el señor Centeno, padre de Ester, la familia está en decadencia, aunque todavía pertenecen a la clase alta de la sociedad capitalina.

Otro momento, separado del hilo central, lo constituye el análisis que hacen Ester y el señor Centeno sobre Charles: cómo llegó a la ciudad, cómo entró en relación con la familia, etc. Todo ello a propósito de la partida de Charles. También se recuerdan aspectos de la vida de Ester, entre los que destaca su odio juvenil por los negros. Estas historias anteriores ocupan capítulos enteros dentro del libro. Hay, asimismo, otras más breves, tales como el noviazgo de Charles con Dora París, desarrollado fragmentariamente, y la historia de la pandilla del Puma, banda de matones a la que perteneció Charles cuando joven. Hay, por fin, una serie de fragmentos desarrollados por los personajes en forma brevísima.

La relación de Charles con Lorena es el aspecto que recibe mayor desarrollo textual. Esto se explica por cuanto esa relación se da en un contexto cultural que es descrito en sus diversos aspectos por el narrador: espacio geográfico y social, creencias, acontecimientos y personajes de ese medio, todo lo cual amplía la presentación del proceso. Le sigue en importancia la narración de la crisis de identidad del personaje. Lo que se muestra en ésta es definido por el narrador como un «aquí» (la ciudad) opuesto a un «allá» (la provincia). La contraposición espacial sirve de soporte a las otras contraposiciones: temporal, cultural-racial y social. Tanto el «allá» como el «aquí» son ricamente caracterizados; pero se nota un ma- 
yor conocimiento del «allá», que comprende aspectos decisivos en la vida del personaje. Se escogen dos momentos importantes en la vida de éste y se les dedica la mayor parte de la narración. Se da, así, la contraposición de dos culturas: la cultura negra, desarrollada en torno a la relación del personaje con una mujer negra, es una cultura asociada a lo rural y provinciano, y la cultura blanca, desarrollada alrededor de la relación del personaje con una mujer blanca. Esta es una cultura de carácter urbano y capitalino. Una vez que el personaje ha desertado de la primera no puede volver, aunque lo intente, y entonces acepta su identidad con la cultura blanca, a pesar de los muchos defectos que encuentra, el principal de los cuales es la actitud racista antinegroide.

La distribución de los acontecimientos en el tiempo presenta tres momentos: a) un pasado lejano, que comprende hechos de la vida de Charles, desde su niñez hasta su partida definitiva del pueblo; también incluye datos sobre los antepasados del personaje: padres, abuelos; b) un pasado cercano, que abarca desde que Charles inicia su relación con Ester hasta que sufre la crisis de identidad, y c) un pasado inmediato, que comprende lo que dura la crisis del personaje. El primero y segundo períodos se subordinan al tercero, con el cual se inicia el texto; por ello esos períodos se dan a través de retrospecciones. A lo largo del relato abundan esas referencias al pasado, sobre todo al pasado lejano. Este rasgo produce una constante fragmentación del acontecimiento, que no sólo se da con respecto a las grandes líneas de acción, sino también a nivel de los detalles. Esta constante ruptura de la linealidad se debe al proceso irregular del recuerdo por parte de los personajes. Es curioso que esa necesidad de ir constantemente al pasado por medio del recuerdo no implica una ubicación temporal o cronológica precisa de los hechos. Estos se dan como sucedidos en algún momento, pero no se especifica en cuál. Eso mismo ocurre con los hechos más cercanos y con los pertenecientes al presente re1ato. Aquí, la identificación se constituye en una marca de escritura.

Todo relato acuña un tiempo dentro de otro, según Genette ${ }^{2}$; en ese sentido, ¿cuánto es el tiempo externo acuñado dentro de esta novela? Básicamente, se trata de la vida de Charles, hasta el momento en que él supera la crisis de identidad. Cuando Lorena está en el hospital, Charles tiene veinticuatro años ${ }^{3}$. Los hechos que suceden después de esto sólo se pueden determinar aproximadamente en el tiempo. No hay fechas ni otras referencias a la edad del personaje, pero éste, durante la crisis de identidad, va a su pueblo natal y encuentra al hijo que tuvo con Victoria. La

${ }^{2}$ Gérard Genette, Figures III (Paris: Éditions du Seuil, 1972), p. 203.

${ }^{3}$ Quince Duncan, Los cuatro espejos (San José, Costa Rica: Editorial Costa Rica, 1973), p. 87. En las citas siguientes sólo se pondrá el número de página. 
novela habla del «niño», y Charles lo toma en brazos. ¿Tendrá cinco o seis años ese niño? Es posible. Si esto es así, ése es el tiempo transcurrido desde que él abandonó el pueblo, pues ya el niño había nacido cuando eso sucedió. Por otra parte, desde que murió Lorena hasta que Charles partió para la ciudad no parece haber transcurrido mucho tiempo: un año o dos a lo sumo, según se desprende de un comentario que de él hace el señor Centeno (p. 10).

De este modo, cuando Charles sufre la crisis tendría aproximadamente treinta años o poco más. Este sería el tiempo básico de la historia contada en la novela. Hay que tener presente que se hacen referencias a una época lejana en el tiempo, cuando se habla de los abuelos de Charles y de los antepasados de Ester. En este último caso se habla de que esos antepasados fueron de los primeros que cultivaron el café en Costa Rica, y este hecho ocurrió alrededor de 1850 . Pero de todo este tiempo sólo se desarrollan plenamente, en la novela, los últimos doce años, es decir, desde el matrimonio de Charles y Lorena. Los hechos anteriores se presentan brevemente. En lo referente a un tiempo exterior, en el que se inscribe la novela, no es posible establecer una relación siquiera aproximada. La elección presidencial de que se habla, cuando se enferma Lorena, puede ser cualquiera de las que se realizan cada cuatro años. No hay datos concretos que permitan establecer fechas del tiempo externo a la obra. Hay indicios vagos, tal como la modernización de la capital, la existencia de algunas tiendas y edificios nuevos; pero eso sólo permite referir los hechos a las últimas décadas de la historia costarricense.

La ambigüedad cronológica refuerza el predominio que tiene en la novela el aspecto subjetivo, personal. Abocado a una búsqueda interior, el personaje no puede dar cuenta detalladamente de lo que pasa a su alrededor. Esto sucede, sobre todo, en lo relativo al aspecto temporal, que es donde hay menos operadores realistas que permitan ubicar el relato en una época determinada. La problemática fundamental del relato es muy personal, casi íntima: el personaje trata de establecer si ha perdido su identidad cultural. Esto le exige un recuento de personas, hechos, espacios y cosas, las cuales le vienen a la mente como un torrente indiferenciado, sobre todo al nivel temporal, porque lo urgente es tenerlos presentes como un apoyo psicológico para superar esa crisis. El nivel de la narración presenta, en forma similar, una serie de rasgos que particularizan, y no sólo en el personaje central, la extrema subjetividad con que se percibe y se desarrolla el mundo novelesco.

El indirecto libre ${ }^{4}$ es la modalidad de discurso más frecuente; también

${ }^{4}$ Genette, op. cit., p. 192. 
la más significativa. Esta modalidad se da asociada con la actividad introspectiva de los personajes, los cuales constantemente reflexionan sobre su pasado en busca de respuestas a su situación. Como se puede notar en el ejemplo que sigue, la modalidad de indirecto no busca tanto la ambiguiedad, que le es inherente al nivel de la persona narrativa, es decir, quién narra, sino más bien poner de manifiesto esa característica de los personajes, que podemos denominar como actividad retrospectiva. En relación con Charles, dice el narrador:

Tristes veintitrés años. Los ochenta de Pete eran mejores, porque el viejo murió sin ver la llegada gradual de los blancos adinerados y de las compañías que succionaron la tierra restante. $\mathrm{Ni}$ vio los acaparadores, que llegaron calladamente y sin que el lodo los manchara, que llegaron invulnerables a la naturaleza cómplice, que además les dio la astucia suficiente para redactar en español documentos legales que sólo ellos comprenden, pero capaces de impresionar al campesino. Así los años hasta sumar veintitrés años que le abrían su huella (p. 33).

En este caso, to que sobresale es el estado de ánimo del personaje, que se pone de manifiesto en su actitud reflexiva. Esta característica es más frecuente en los personajes negros de la novela, inmersos en la evocación de su pasado.

En lo relativo a la visión a través de la cual se presenta el mundo, predomina, con escasas excepciones, la focalización interna variable ${ }^{5}, y$ dentro de esta modalidad hay un personaje sobre el que se da más. La focalización interna es lógica en un texto en que el pasado se reconstruye en la mente de cada personaje y para los fines de éste. Se da, así, una visión fuertemente personal, que va mostrando un mundo que no intenta constituirse por sí mismo, sino por lo que significa para cada personaje. Hay capítulos enteros totalmente focalizados en Charles, quien, sin lugar a dudas, es el personaje central del relato. Este predominio se ve confirmado también en otros niveles del texto. Hay una focalización significativa sobre Lorena y también sobre Christian, a través de cuyos recuerdos se conocen hechos de su pasado. También se focaliza, en alguna medida, sobre Ester y sobre el señor Centeno, por medio de los cuales se conocen aspectos de la vida de Charles en la ciudad.

En esta novela se dan cuatro capítulos con narrador externo y siete capítulos con narrador interno. Con esta última modalidad se inicia el relato y también concluye. Los capítulos con narrador externo a la historia quedan enmarcados, así, dentro de la modalidad homodiegética ${ }^{6}$; esto,

\footnotetext{
${ }^{5}$ Idem, p. 207.

${ }^{6}$ Idem, p. 252.
} 
no obstante, se da en un nivel de organización externa del texto, pues, lógicamente, un relato homodiegético no puede ser marco de uno heterodiegético ${ }^{7}$. En otras novelas son comunes los casos en que una instancia narrativa externa cede la palabra al personaje y se crea, así, una instancia narrativa interna. Pero no es éste el caso de Los cuatro espejos, pues aquí la instancia homodiegética es autónoma con respecto a la otra y es la que cierra el relato. ¿Cómo se explica esto? Desde el inicio hasta el capítulo quinto de la novela, el material diegético se distribuye entre los dos tipos de narrador: el narrador homodiegético presenta la crisis de identidad de Charles y las andanzas de este personaje durante dicha crisis. Se trata de un narrador autodiegético ${ }^{8}$, pues es el mismo personaje quien narra sus experiencias. Por su parte, el narrador externo presenta la relación de Charles con Lorena, así como el papel de Christian Bowman en esa relación. A partir del capítulo sexto, este último narrador presenta la reacción de Ester ante la crisis y la ausencia de Charles. También aquí se completan aspectos de la vida de este personaje, que él ha venido recordando como narrador autodiegético. De modo que los dos tipos de narrador no se limitan a aspectos distintos de la historia, sino que cada uno invade aspectos del otro. Esto aumenta a partir del capítulo séptimo, en que el relato vuelve a ser presentado por el narrador homodiegético, o sea, Charles, el cual retoma lo relativo a su crisis de identidad, pero también narra aspectos relativos a su vida con Lorena y con las otras mujeres, aspectos que venía desarrollando el otro tipo de narrador.

A partir del capítulo séptimo, y hasta el final, es Charles quien narra. Ahora bien: ¿a qué se deben esos cambios en la persona narrativa? La explicación está, parcialmente, en el aspecto de la focalización. Es evidente que Charles, como personaje, no podía narrar los hechos relativos a Christian Bowman, focalizados en este personaje; esto lo pondría en una condición inaceptable: la de conocer los pensamientos y sentimientos de otros personajes del mismo nivel diegético ${ }^{9}$ que él. Por eso, con respecto a Christian Bowman en el capítulo tercero, con respecto a Ester en el sexto e inclusive con respecto a Lorena en el capítulo quinto, se hacía necesario un narrador heterodiegético con acceso ilimitado a la interioridad del personaje. Aun así, queda por explicar lo del capítulo segundo, en el que se narra parte de la relación de Charles y Lorena, hecho que se da con focalización predominante en Charles, $y$, sin embargo, el capítulo está presentado por un narrador heterodiegético, ¿por qué?, ¿simple variedad?, ¿como marca de escritura? Es posible.

${ }^{7}$ Ibidem.

Idem, p. 253.

${ }^{9}$ Idem, p. 72. 
Ahora bien: volviendo a la relación entre la instancia homodiegética y la heterodiegética, aquélla no está subordinada a ésta, sino que es yuxtapuesta a un mismo nivel jerárquico en el relato, instancias unificadas por medio del personaje central. Se pueden considerar, pues, como dos relatos que convergen al nivel de la historia, pero que no convergen al nivel de la narración. El sentido de esto sería una experimentación técnica no directamente ligada a la presentación de la historia, la cual no parece perder ni ganar con tal recurso. Se trata, en todo caso, de rasgos del relato contemporáneo, en concordancia con lo cual se dan otros más.

Aparte de los ya vistos, como la focalización interna, por medio de la cual el narrador desplaza hacia el personaje la visión de los acontecimientos, con lo que la instancia narrativa clásica ve así disminuidas sus prerrogativas en la presentación de una historia que ya no maneja en su totalidad, se dan las referencias al proceso narrativo, que son abundantes en los capítulos con instancia narrativa homodiegética. Véanse algunos ejemplos. Dice Charles:

Mi vida ha tenido sus altibajos, fracasos, esfuerzos, regresos, en fin, ya los iré contando.

Lucas Centeno Vidaurre es un médico distinguido. Se me olvidaba señalar que es mi suegro.

Pero les estaba contando sobre nuestra entrada triunfal en el Teatro Nacional (p. 10).

Así, como éstos, hay muchos otros casos en que el personaje se refiere a su actividad narrativa, al hecho de «contar». A veces se refiere a la corrección del discurso y, por ende, a la escritura. Véanse los casos siguientes:

... sobre sus ojos ardientes se posaba la luz. Otra vez me puse cursi, ¿no es cierto? Miren no más: sobre sus ojos se paraba la luz. Ni que esto fuera poema (p. 13).

Aquí no hay duda de que se trata de una alusión al hecho de escribir. También en este otro caso:

En la temprana luz - ya me estoy volviendo cursi otra vez-. Lo que pasa es que tengo manía de poeta. Quiero decir que el sol apenas alumbraba. No, no es eso. Era una luz, temprana, suena mejor. Es mucho más exacto (p. 18).

También son muy abundantes, en los capítulos homodiegéticos, las referencias al narratario, convocado explícitamente como interlocutor o 
como lector. Esta función se da en muchos casos unida a las referencias a la escritura. Véanse los siguientes ejemplos:

Ustedes me perdonarán lo cursi que soy, porque eso de decirle simpática a una mujer es cosa cursi. Todos dicen eso. ¿No es cierto? Pues bien, si todos lo dicen entonces es cursi. Yo soy cursi, ya lo verán. Pero por lo menos no me gusta serlo. ¿De qué les estaba hablando?... (p. 11).

En algunos casos, el personaje narrador casi entabla un diálogo con el lector. Véase el ejemplo siguiente:

¡Vamos! Supóngase que ustedes tienen una casa y han tenido que hacer alguna vuelta para conseguirla. Luego ustedes van a creer que yo los estoy atacando. Pero no es eso... (p. 17).

También hay referencias al narratario en el caso del narrador heterodiegético; pero no son tan explícitas como las anteriores. Los dos tipos de narrador ponen de manifiesto sus preferencias, su estado anímico, a través de valorizaciones de los diversos aspectos de la historia. Lo hace con mayor frecuencia al narrador personaje. Sin embargo, no se trata de una expresividad lírica, presente en la descripción del paisaje, por ejemplo. Esta novela no se acerca a lo lírico. Predomina más bien la representación de acciones y el análisis. En éstas se da la expresividad, pero totalmente subordinada a la función épica y narrativa.

La función ideológica es la más abundante en el texto novelesco. Se da tanto en el narrador homodiegético como en el heterodiegético. Véanse algunos ejemplos: «Me sentí incapaz de romper las cadenas, limitado por designios externos a mí. Los hombres no deberían tener límites, porque tales regulaciones son otra sutil manera de negar su humanidad» (p. 8). Se trata de una generalización que, como tal, no hace avanzar la historia, sino que apunta a una característica del narrador. Véase otro caso: «Hay agravios demasiado hondos para perdonar, al menos que uno quiera renunciar a la dignidad. Porque perdonar a veces supone renunciar a la propia dignidad» (p. 9). Se trata, obviamente, de otra generalización.

E1 narrador heterodiegético también ejercita la función ideológica sobre diversos aspectos. En el siguiente ejemplo, el narrador comenta lo que siente Charles:

Era más de lo que un hombre normal -aunque fuese pastorsiempre que sea normal pudiese tolerar. Demasiado. Sí, hay que sopesar bien la resistencia de un hombre como Charles enfrentado a la situación de su ser querido (p. 38). 


\section{RESUMEN E INTERPRETACIÓN DE RASGOS}

En relación con la historia, el rasgo más novedoso a nivel de técnicas narrativas es la fragmentación del acontecimiento, que responde no sólo al proceso discontinuo del recuerdo de los personajes, de los cuales depende el desarrollo de buena parte de la historia, sino a una voluntad explícita de diferenciación del texto con respecto a otros textos anteriores. En consonancia con dicha fragmentación se da un juego de retrospecciones que afecta capítulos enteros del relato y que responde también a la oscilación del recuerdo de los personajes. La retrospección como tal no es un rasgo típico del relato contemporáneo; no obstante, puede serlo si, como en este caso, su empleo responde al intento de cifrar en el personaje los hechos fundamentales de la diégesis.

Otro rasgo interesante es el uso del sumario para recordar hechos narrados, y que responde al carácter de revisión del pasado que tiene la novela. Parece ser necesario que el personaje, en todo momento, tenga presente, aunque sea resumidamente, ese pasado, para determinar su influencia en el presente. La novela se constituye, realmente, en una búsqueda en el pasado. Búsqueda nostálgica a veces, como en el caso de Christian Bowman cuando reflexiona sobre Lorena; búsqueda para superar experiencias que lo atan, como es el caso de Charles, quien, después del viaje a su vida anterior, regresa definitivamente a su condición actual y la acepta. Búsqueda nostálgica también en el caso de Lorena, quien sospecha que ya no volverá a su pueblo natal. El pasado encadena a estos personajes, y ellos lo tienen presente en todo momento. Con esta situación se relaciona también la modalidad repetitiva del relato, que surge de esa necesidad apuntada con respecto al pasado y que, a nivel de narración, constituye un recurso de refuerzo de la misma necesidad.

Hay una oscilación entre la presentación del acontecimiento como historia real o como novela. A favor de la primera posibilidad se dan las informaciones especiales detalladas sobre los lugares en que ocurre la acción. Se describen las calles, los edificios, se nombran los pueblos sin variación, se describen los medios de transporte, las condiciones climatológicas, etc., y todo ello tiene como función anclar el relato en lo real, producir el efecto de realidad. Los lugares novelescos coinciden con lugares reales. La segunda posibilidad cuenta a su favor con la vaguedad en la ubicación temporal de los hechos novelescos.

No es posible establecer siquiera fechas aproximadas para el inicio y el final de la historia que se narra. Así, aunque la recuperación del pasado figura como un intento fundamental en la obra, se trata de una visión 
más social que histórica de ese pasado. Así, pues, un hecho social como la contraposición cultural y étnica se enfatiza en su dimensión humana y social y no tanto en su dimensión histórico-cronológica. Entre estas dos posibilidades, la novela se define por la primera y, de paso, aprovecha la ambigüedad para proponerse como hecho novelesco, no real.

A nivel de discurso, en esta novela es fundamental la visión narrativa de carácter personal. Aunque hay dos tipos básicos de narrador, en cualquier caso la historia se presenta a través de los personajes. La focalización interna busca eso precisamente: presentar un mundo visto por tal o cual personaje. Ya se sabe que hay predominio de éstos, pero para el carácter personalizado del relato esto no tiene que ver. A favor de este tipo de visión se da también el discurso indirecto libre, asociado a la actividad reflexiva de los personajes.

Quizá el aspecto más novedoso de las técnicas novelescas lo constituye el de la persona narrativa, en la cual se yuxtaponen dos tipos de narrador sin relación entre sí. Esto es curioso porque en otros muchos relatos se dan diversos tipos de narrador en el mismo texto, pero hay una jerarquía, ya sea explícita o implícita. Aquí no es posible jerarquizar los dos tipos, a no ser por decisión arbitraria. Este es un rasgo que cobra sentido en relación con el proceso de escritura. El novelista actual tiene una especie de necesidad de dejar constancia de que lo que escribe es literatura y no otra cosa. En este sentido hay una serie de señales en los textos, que van desde el comentario a otros textos literarios hasta la reflexión sobre el propio proceso creativo.

En el caso de esta novela, como ya se vio al tratar de las funciones del narrador, las reflexiones sobre el texto son muy abundantes: de corrección, de identificación e incluso de crítica; tal es el caso de los comentarios que hace Charles sobre un libro de un autor negro. Este autor no es otro que Quince Duncan, y el libro es un tomo de cuentos escritos por él en los inicios de su actividad literaria. Las alusiones al proceso de escritura son uno de los rasgos comunes de la nueva novela costarricense. Responden a una actitud contraria al objetivismo realista de la época anterior y son síntoma de una conciencia más clara del escritor con respecto al tipo de material con el cual trabaja.

Predomina aquí un tipo de personaje joven, problemático, vuelto sobre sí mismo para encontrar el sentido de su vida. Pero el personaje de esta novela parece tener otros motivos para su angustia. La situación del negro en Costa Rica, históricamente, ha sido la de una segregación. Llegado como mano de obra para construir los ferrocarriales, se radica en la zona más inhóspita y más abandonada del país. Así sobrevive casi un siglo sin que se le preste atención, hasta que el nuevo Estado surgido alrededor de 
1950 se preocupa por la situación general de esta provincia atlántica. Limón, entonces, participa de la promoción educativa nacional, y los negros, a quienes se les prohibía residir en la meseta, pueden por fin venir a estudiar en la universidad e incluso a vivir en la capital. Muchos de los que van a estudiar se alejan definitivamente de sus lugares de origen y se adaptan a las costumbres urbanas. Pero el negro sigue siendo visto como negro antes que como persona, y nace aquí una frustración difícil de superar, porque ya no puede volver al ambiente cultural de donde vino, pero tampoco puede compartir plenamente el mundo de los blancos. De aquí parte la propuesta novelística de Los cuatro espejos, la cual intenta reflejar, en un caso concreto, cómo se da ese problema de identidad en el negro costarricense. La particularidad de esta novela es que Duncan no pone a sus personajes en relación con los sectores bajos de la ciudad, como en la realidad ocurre, sino que los ubica en la alta sociedad, al contraer matrimonio el protagonista con una muchacha de familia rica y distingutida. Charles vivió en zonas marginales de la ciudad cuando vino al colegio, pero en la novela ésos son recuerdos lejanos que palidecen ante la nueva situación del personaje, su pertenencia a la alta sociedad. El autor saca partido de esta situación y trata de hacer una crítica de la vida de esa sociedad a la que él pertenece. Sociedad de médicos, profesores y diputados, de fiestas y galas, etc. Es una crítica bien lograda; pero el lector siente que se trata de un ambiente artificial, no vivido, un ambiente que no puede competir en su presentación con el ambiente negro, detalladamente descrito por el narrador. Dentro de su nueva situación, y mientras recorre la ciudad angustiado por la crisis de identidad, sí logra el personaje calar en ambientes urbanos típicos: la vida en las tabernas, en los clubes nocturnos, en las calles a ciertas horas de la noche.

La solución de la crisis de identidad por medio de la aceptación de otra cultura, simbolizada en Ester, la mujer blanca y de alcurnia, con quien Charles contrae matrimonio, funciona como planteamiento de fondo no sólo para la novela Los cuatro espejos, sino también para otros casos. Hay que tener presente que en Final de calle, novela de 1978, 1a problemática del negro como conflicto étnico y social, e incluso personal, ya no ocupa más que una brevísima referencia. Esto parece ser un indicio de que, con la aceptación del personaje de Los cuatro espejos de su nueva condición social y cultural en el seno de la sociedad capitalina, se da por resuelto el conflicto, y que esa aceptación se plantea precisamente como solución, por lo menos a nivel personal, del conflicto étnico del negro costarricense. 